\title{
Analytical measurements of fission products during a severe nuclear accident
}

\author{
D. Doizi ${ }^{1}$; S. Reymond la Ruinaz ${ }^{1}$; I. Haykal ${ }^{1}$; L. Manceron ${ }^{2,3}$; A. Perrin ${ }^{4}$; V. Boudon ${ }^{5}$ J. Vander Auwera ${ }^{6}$; F. \\ Kwabia tchana $^{7}$; M. Faye ${ }^{2}$
}

\begin{abstract}
The Fukushima accident emphasized the fact that ways to monitor in real time the evolution of a nuclear reactor during a severe accident remain to be developed. No fission products were monitored during twelve days; only dose rates were measured, which is not sufficient to carry out an online diagnosis of the event. The first measurements were announced with little reliability for low volatile fission products. In order to improve the safety of nuclear plants and minimize the industrial, ecological and health consequences of a severe accident, it is necessary to develop new reliable measurement systems, operating at the earliest and closest to the emission source of fission products. Through the French program ANR « Projet d'Investissement d'Avenir ", the aim of the DECA-PF project (diagnosis of core degradation from fission products measurements) is to monitor in real time the release of the major fission products (krypton, xenon, gaseous forms of iodine and ruthenium) outside the nuclear reactor containment. These products are released at different times during a nuclear accident and at different states of the nuclear core degradation. Thus, monitoring these fission products gives information on the situation inside the containment and helps to apply the Severe Accident Management procedures. Analytical techniques have been proposed and evaluated. The results are discussed here.
\end{abstract}

Index Terms - severe accident, fission products, xenon, krypton, iodine, ruthenium, molecular spectroscopy.

\section{INTRODUCTION}

$\mathrm{T}$ HE Fukushima accident emphasized the need for real time monitoring of fission products [1] to get information on the situation inside the containment in the case of severe accidents. The aim of the DECA-PF project (diagnosis of core degradation from fission products measurements) launched through the French program ANR « Projet d'Investissement d'Avenir », is to propose analytical techniques able to measure major fission products which are released at different time during a nuclear accident and at different states of the nuclear core degradation. Gamma spectrometry is used as the reference technique. A prototype has been designed and will be implemented at the outlet of the U5 filter. Besides Gamma

${ }^{1}$ Den-Service d'Etude du Comportement des Radionucléides (SECR), CEA, Université Paris-Saclay, F-91191, Gif-sur -Yvette, France.

${ }^{2}$ Société Civile Synchrotron SOLEIL, L'Orme des Merisiers, St-Aubin BP48, 91192 Gif-sur-Yvette Cedex, France.

${ }^{3}$ MONARIS, UMR 8233, Université Pierre et Marie Curie, 4 Place Jussieu, case 49, F-75252 Paris Cedex 05, France.

${ }^{4}$ LMD UMR 8539, ARA/ABC(t)/LMD/IPSL Ecole Polytechnique RD 36, 91128 Palaiseau Cedex, France. spectrometry, molecular absorption spectrometry has been proposed for the measurement of gaseous forms of iodine and ruthenium. It allows on line chemical speciation of the gaseous forms of fission products and could enable their remote sensing. It has been evaluated and is the subject of this paper.

- $\quad$ For fission gases such as xenon and krypton, micro gas chromatography (micro GC) measurements have been proposed and characterized from the point of view of detection limits and ease of installation on the chimney of the nuclear plant.

- For molecular and organic iodine measurements, optical techniques such as Fourier Transform Infrared (FTIR) spectrometry and Incoherent BroadBand Absorption Spectroscopy (iBBCEAS) have been proposed. To face the low detection limits needed for organic iodine, photoacoustic spectroscopy has also been proposed and evaluated.

- For gaseous ruthenium measurements, Fourier Transform InfraRed (FTIR) spectrometry has been proposed and evaluated.

\section{SEVERE ACCIDENT}

The severity of the accident depends on the degree of damage of the fuel and the degree of confinement loss. During a severe accident, various physical phenomena may occur and lead to the release of fission products from the fuel to the containment [2]:

- emptying of the core ("uncovering" or "dewatering"),

- heating of the fuel rods, and then oxidation of the cladding by the water steam (very exothermic reaction), - degradation of the fuel rods and rupture of the claddings,

${ }^{5}$ Laboratoire Interdisciplinaire Carnot de Bourgogne, UMR 6303 CNRSUniversité de Bourgogne, 9 avenue Alain Savary, BP 47870, F-21078 Dijon Cedex, France.

${ }^{6}$ Service de Chimie Quantique et Photophysique C.P. 160/09 Université Libre de Bruxelles, 50 avenue F.D. Roosevelt - 1050 Bruxelles - Belgique

${ }^{7}$ Laboratoire Inter-Universitaire des Systèmes Atmosphériques (LISA), UMR 7583, CNRS et Universités Paris Est et Paris Diderot, Institut Paul Simon Laplace, 61 Av. du Général de Gaulle, 94010 Créteil, France. 
- fusion of materials (claddings, fuels, structural materials),

- volatilization and release of fission products, which are transported in gaseous or aerosol forms, in the primary circuit, by the hot gases from the core (steam and hydrogen), and then deposited inside the primary circuit and / or transferred in the containment,

- breakthrough of the vessel and erosion of the basemat, due to the corium-concrete interaction,

- transfer of certain fission products, in gaseous or aerosol forms outside of the containment, causing radioactive contamination of the environment (source term). Filtered containment venting systems are implemented in order to avoid a large containment failure and to minimize the release of radioactive materials into the environment.

Another phenomenon can play a key role in the development of a severe accident: an air inlet into the reactor vessel [3]. Studies [4] [5] showed that, just after the breaking of the vessel bottom, air is expelled from the cavity to the surrounding areas due to high flows of gas from the corium-concrete interaction $\left(\mathrm{H}_{2}, \mathrm{CO}_{2}, \mathrm{CO}\right)$.

The contact between irradiated fuels and air can lead to the production of volatile species of ruthenium especially $\mathrm{RuO}_{4}$.

\section{XENON AND KRYPTON MEASUREMENTS}

In the case of the rupture of fuel claddings, fission gases are produced particularly xenon and krypton. The use of molecular spectrometry to measure on line these gases is not easy and would lead to rather complex experimental setups. A robust technique based on gas chromatography has been evaluated. A micro GC Agilent 490 has been chosen to measure xenon and krypton in various gas mixtures containing well known quantities of xenon and krypton. The linearity of the detector response versus concentration has been measured and a detection limit has been estimated for each gas.

A value of $\sim 1 \mathrm{ppm}$ has been measured for both gas. This value is in good agreement with the requirements of the source term calculated in the project.

The same technique has also been used to measure $\mathrm{CO}$ and $\mathrm{CO}_{2}$ gases, signatures of an interaction between the corium and the concrete at the ppm level, although molecular spectroscopy could have also been used in this particular case.

\section{FTIR MEASUREMENTS}

The Fourier transform infrared spectrometry (FTIR) was chosen to measure gaseous organic iodine and ruthenium tetraoxide. The species are infrared active and shows absorption bands around 10 microns, a spectral window interesting for atmospheric measurements. This technique is robust, panoramic, and can be used on line. It also allows quantitative measurements when spectral data (positions, absorption cross sections) are available. In our case, such data are unknown and it was necessary to determine them. For that purpose, high resolution infrared measurements were carried out for $\mathrm{CH}_{3} \mathrm{I}$,
${ }^{102} \mathrm{RuO}_{4}$ and natural $\mathrm{RuO}_{4}$ with Bruker IFS 125 HR Fourier transform spectrometer available at the infrared AILES beamline at the French synchrotron facility SOLEIL, relying on synchrotron radiation, and at LISA Créteil. Theoretical calculations and experimental measurements have been performed to characterize line positions and intensities for each molecule, in collaboration with ICB Dijon, LISA Créteil and UL Bruxelles. The results of this experimental and theoretical work have been published [6-9].

FTIR spectrometry can be used to measure ruthenium in gaseous forms. For organic iodine, the low absorption cross section and the low quantities to be measured would require a very long optical path length to satisfy the specifications of the source term. An alternative way to measure organic iodine was evaluated: photoacoustic spectroscopy.

\section{PHOTOACOUSTIC MEASUREMENT OF ORGANIC IODINE}

Photoacoustic spectroscopy is a robust and sensitive technique. It relies on the absorption of a modulated laser beam by the gas to be studied. In the infrared domain, a vibrational excitation occurs which is followed by a collisional de-excitation creating a transient warming and hence an acoustic wave. This acoustic wave is measured with a microphone.

Our setup uses a $\mathrm{CW}$ tunable $\mathrm{CO}_{2}$ laser, Lasy $4 \mathrm{G}$ from Access Laser Company, which is triggered at $\sim 1 \mathrm{kHz}$.

The $\mathrm{CO}_{2}$ output wavelength is tuned to an absorption band of $\mathrm{CH}_{3} \mathrm{I}$ and sent in the photoacoustic cell made by Aerovia, Reims, France. The acoustic signal is measured using a synchronous detection at the modulation frequency of the laser. A mixture of 5 ppm $\mathrm{CH}_{3} \mathrm{I}$ in nitrogen, Air Products, is used. A detection limit of about $30 \mathrm{ppb}$ has been measured. This value meets the requirements of the Source term. This technique may also be used to measure $\mathrm{RuO}_{4}$ and iodine. Work is in progress to validate these possibilities.

\section{MOLECULAR IODINE MEASUREMENT}

Molecular iodine is not infrared active but it exhibits a strong absorption spectrum in the visible range. Due to the low values of the source term, a sensitive technique is necessary to measure iodine.

Incoherent BroadBand Cavity Enhanced Absorption Spectroscopy (iBBCEAS) has been proposed and is under evaluation. This technique has already been successfully used in nuclear [10] and environmental studies [11]. The experimental setup is composed of a green LED (Light Emitting Diode), LuxeonStarLEDs, which is stabilized in current and in temperature using Arroyo instruments drivers. It delivers light between 500 and $600 \mathrm{~nm}$. Light is focused in a high finesse optical cavity. The transmitted light is focused on an Ocean Optics HR 2000 spectrometer and analyzed. The experimental set up is under evaluation at the laboratory. 


\section{CONCLUSION}

Source term specifications can be achieved using molecular absorption spectrometry, especially visible and FTIR spectrometries. Results of this work can be used to design new specific sensors to detect and quantify quickly and precisely the amount of fission products at the chimney of a nuclear reactor in case of filtered containment decompression.

The work is in progress in order to determine if one single prototype could measure all gaseous fission products together. This prototype could rely on airborne photoacoustic spectroscopy.

The main advantage of this solution would be to activate the prototype only in the case of severe accidents.

\section{ACKNOWLEDGMENT}

The DECA-PF project, launched end of 2013 for 3 years, is sponsored by the French government "Investments for the future" program through the grant ANR-11-RSNR-0003 supervised by the French National Research Agency (ANR) under the "Research in Nuclear Safety and Radioprotection" (RSNR) research initiative.

\section{REFERENCES}

[1] Report of the IAEA expert mission in June 2011

[2] C. Mun, "Etude du comportement du produit de fission ruthénium dans l'enceinte de confinement d'un réacteur nucléaire, en cas d'accident grave", PhD, Université de Paris XI (2007).

[3] Powers D., Kmethyk L.N. and Schmidt R.C., "A review of the technical Issues of air ingression during severe reactor accidents", NUREG/CR $6218,1994$.

[4] Seropian, C., "Analysis of the potential for in-vessel air ingress during a severe accident in a PWR 900 MWe", Note technique IRSN/DPAM/SEMIC/LEPF, 2003.

[5] Freydier, P., Rousset, J.L., "Evaluation of Air Ingress in the Reactor Vessel with the SATURNE Code-SARNET-ST-P19"- EdF n ${ }^{\circ} \mathrm{HI}-$ 83/05/006/A, 2006.

[6] H S. Reymond-Laruinaz, M. Faye, V. Boudon, D. Doizi, L. Manceron, "High-resolution infrared spectroscopy and analysis of the $v 2 / v 4$ bending dyad of ruthenium tetroxide", J. of Mol. Spectroscopy, 336, (2017), 2935 .

[7] A. Perrin, I. Haykal, F. Kwabia Tchana, L. Manceron, D. Doizi, G Ducros, "New analysis of the $v 6$ and $2 v 3$ bands of methyl iodide $\left(\mathrm{CH}_{3} \mathrm{I}\right)$ ", J. of Mol. Spectroscopy, 324, (2016), 28-35.

[8] I. Haykal, D. Doizi, V. Boudon, A. el Hilali, L. Manceron, G. Ducros, "Line positions in the $v 6=1$ band of methyl iodide: validation of the C3v TDS package based on the tensorial formalism", I. Haykal, D. Doizi, V. Boudon, A. el Hilali, L. Manceron, G. Ducros, J. of Quant. Spectros. and Radiat. transfer, 173, (2016), 13-19.

[9] I S. Reymond-Laruinaz, V. Boudon, L. Manceron, L. Lago, D. Doizi,"Infrared Spectrocopy of Ruthenium Tetroxide and High-resolution analysis of the $v 3$ band", J. of Mol. Spectroscopy, 2015, 315 (2015) 4654.

[10] O. Johansson, H. Mutelle, A. E. Parker, S. Batut, P. Demaux, C. Schoemaecker and C. Fittschen, "Quantitative iBBCEAS measurements of $\mathrm{I}_{2}$ in the presence of aerosols", Appl. Phys. B, vol 114, pp.421-432, 2014
[11] S. M. Ball, A. M. Hollingsworth, J. Humbles, C. Leblanc, P. Potin, and G. McFiggans, "Spectroscopic studies of molecular iodine emitted into the gas phase", Atmos. Chem. Phys., 10, 6237-6254, 2010. 